\title{
NUTRIENT NITROGEN MANAGEMENT FOR DISEASE CONTROL IN STRAWBERRY
}

\author{
M. WALTER ${ }^{1}$, B. BRAITHWAITE ${ }^{1}$, B.J. SMITH ${ }^{2}$ and G.I. LANGFORD ${ }^{1}$ \\ ${ }^{I}$ The Horticulture and Food Research Institute of New Zealand Ltd \\ (HortResearch), PO Box 51, Lincoln, New Zealand \\ ${ }^{2}$ USDA-ARS, Highway 26W, Poplarville, MS 39470, USA
}

Corresponding author:mwalter@hortresearch.co.nz

\begin{abstract}
Botrytis cinerea and Colletotrichum acutatum are important strawberry pathogens. Nitrogen (N) application can increase yield, but also susceptibility to pathogens. Strawberry plants ('Camarosa' and 'Ventana') were grown in sand, fertilised with base nutrients plus ammonium nitrate, ammonium sulphate or calcium nitrate at low (40 ppm N) and high $(140 \mathrm{ppm} \mathrm{N})$ concentration. Controls consisted of base nutrients only and water only. Flower production, fruit yield and berry size all increased with increasing $\mathrm{N}$-concentration, but $\mathrm{N}$-source itself was not important. Disease susceptibility was affected by both $\mathrm{N}$-concentration and N-source. At high $\mathrm{N}$-concentration, $C$. acutatum fruit lesions were largest in ammonium sulphate treatments $>$ ammonium nitrate $>$ calcium nitrate; Botryits cinerea lesions were largest in ammonium nitrate $>$ ammonium sulphate $>$ calcium nitrate. Similar trends were observed for leaf susceptibility to the two pathogens. These data suggest that calcium nitrate may be a suitable source of nitrogen, helping growers to reduce disease risk.

Keywords: Botrytis cinerea, Colletotrichum acutatum, ammonium sulphate, ammonium nitrate, calcium nitrate, disease susceptibility.
\end{abstract}

\section{INTRODUCTION}

Berries are high value horticultural crops. However, they can suffer substantial crop loss from pathogens, in large because of infections of grey mould (Botrytis cinerea) and anthracnose (Colletotrichum spp.) (Maas 1998). It is well established that nitrogen (N) regulates yield, but it can also increase susceptibility to grey mould and anthracnose infections. Howard et al. (1992), for example, reported that growing strawberry plants in soils with low nitrogen levels can reduce the severity of anthracnose. In grapes, Keller et al. (2001) found that nitrogen increased bunch stem necrosis, $B$. cinerea bunch rot and yield.

The research described in this paper investigated the relationship between nutrient-N concentration, N-type and susceptibility of strawberry fruit and leaves to anthracnose and grey mould.

\section{MATERIALS AND METHODS}

Disease susceptibility of strawberry plants fertilised with base nutrients plus ammonium nitrate, ammonium sulphate or calcium nitrate at low $(40 \mathrm{ppm} \mathrm{N})$ and high $(140 \mathrm{ppm} \mathrm{N})$ concentration was studied. Strawberry was used as the model crop because of ease in plant availability, ease of production using potted plants in a glasshouse, and continuous flowering and fruiting for several months. The two cultivars assessed were 'Camarosa' and 'Ventana'. The exact nutritional compositions for the eight different nutrient treatments are presented in Table 1. 
TABLE 1: Composition of nutrient solutions (ppm) used in the eight strawberry disease management treatments. The $\mathrm{pH}$ was adjusted to $6.2 \mathrm{using}$ hydrochloric acid (1 N HCl).

\begin{tabular}{lcccccccc}
\hline & & \multicolumn{7}{c}{ Actual nutrient concentrations (ppm) } \\
\cline { 3 - 8 } Treatment & $\mathrm{N}-$ source & $\mathrm{N}$ & $\mathrm{P}$ & $\mathrm{K}$ & $\mathrm{Ca}$ & $\mathrm{Mg}$ & $\mathrm{S}$ & $\mathrm{Cl}$ \\
\hline Ammonium sulphate & $\mathrm{NH}_{4} \mathrm{SO}_{4}$ & 40 & 31 & 64 & 81 & 24 & 88 & 144 \\
Ammonium sulphate & $\mathrm{NH}_{4} \mathrm{SO}_{4}$ & 139 & 31 & 64 & 81 & 24 & 202 & 144 \\
Ammonium nitrate & $\mathrm{NH}_{4} \mathrm{NO}_{3}$ & 40 & 31 & 64 & 81 & 24 & 42 & 144 \\
Ammonium nitrate & $\mathrm{NH}_{4} \mathrm{NO}_{3}$ & 140 & 31 & 64 & 81 & 24 & 42 & 144 \\
Calcium nitrate & $\mathrm{CaNO}_{3}$ & 40 & 31 & 64 & 49 & 24 & 42 & 0 \\
Calcium nitrate & $\mathrm{CaNO}_{3}$ & 140 & 31 & 64 & 172 & 24 & 42 & 0 \\
Nil control & Water only $_{\text {Nutrient control }}$ & 0 & 0 & 0 & 0 & 0 & 0 & 0 \\
Base nutrients & & 0 & 31 & 64 & 81 & 24 & 57 & 144 \\
\hline
\end{tabular}

${ }^{1} \mathrm{~N}=$ nitrogen, $\mathrm{P}=$ phosphorus, $\mathrm{K}=$ potassium, $\mathrm{Ca}=$ calcium, $\mathrm{Mg}=$ magnesium, $\mathrm{S}=$ sulphur, $\mathrm{Cl}=$ chloride. Micronutrients were present in all treatments (except nil control) at the following concentrations: $\mathrm{Fe}=$ iron $(2.8 \mathrm{ppm}), \mathrm{B}=$ boron $(0.54 \mathrm{ppm}), \mathrm{Mn}=\operatorname{manganese}(0.55 \mathrm{ppm}), \mathrm{Cu}=\operatorname{copper}(0.06 \mathrm{ppm}), \mathrm{Zn}=\mathrm{zinc}(0.1 \mathrm{ppm})$, Mo $=$ molybdenum $(0.05 \mathrm{ppm})$. All nutrient salts were sourced from Evergreen Horticulture and Hydroponics, Christchurch, and were of fertiliser grade. The nonnitrogen salts used were potassium dihydrogen phosphate $\left(\mathrm{KH}_{2} \mathrm{PO}_{4}\right)$, sodium dihydrogen phosphate $\left(\mathrm{NaH}_{2} \mathrm{PO}_{4}\right)$, potassium sulphate $\left(\mathrm{KSO}_{4}\right)$, calcium chloride $\left(\mathrm{CaCl}_{2}\right)$, magnesium sulphate $\left(\mathrm{MgSO}_{4}\right)$, ferric ethylenediaminetetraacetic acid (FeEDTA), borax pentahydrate $\left(\mathrm{Na}_{2} \mathrm{~B}_{4} \mathrm{O}_{7} .5 \mathrm{H}_{2} \mathrm{O}\right)$, manganese sulphate $\left(\mathrm{MnSO}_{4}\right)$, copper sulphate $\left(\mathrm{CuSO}_{4}\right)$, zinc sulphate $\left(\mathrm{ZnSO}_{4}\right)$, and sodium molybdate $\left(\mathrm{Na}_{2} \mathrm{MoO}_{4}\right)$.

${ }^{2} \mathrm{All}$ nutrients excluding nitrogen.

The experiment was conducted in a heated greenhouse $\left(16-23^{\circ} \mathrm{C}\right)$ at Lincoln University. Plants were obtained as bare rooted runners from a commercial runner grower in Katikati, New Zealand. Roots were cut to approximately $10 \mathrm{~cm}$ length and all leaves removed except for 1-2 emerging trifoliate leaves. Plants were potted into washed concrete sand (46\% < $1 \mathrm{~mm}, 21 \% 1-2 \mathrm{~mm}, 33 \%>2 \mathrm{~mm}$; Fulton Hogan, Christchurch) on 18 July 2007 into 1.2 litre plastic pots (RX Plastics, New Zealand). The sand surface was covered with a $2 \mathrm{~cm}$ layer of coarse road chip (5-7 mm, Fulton Hogan, Christchurch) to eliminate algae growth. Plants were watered immediately after planting. First nutrient solutions were applied on 20 July 2007 . Nutrients were applied topically onto the gravel of each individual pot using a measuring cylinder. Feeding was conducted 3 times per week (Monday, Wednesday and Friday) initially with $30 \mathrm{ml}$ of nutrient solution, which then increased to $50 \mathrm{ml}$ on 13 August 2007. Nutrient solutions were kept in the dark in sealed plastic containers in the greenhouse. Plants were provided with additional water as required from 24 September 2007 onwards. All emerging flowers were removed from planting until 10 August 2007. A hive of bumble bees (Bombus terrestris; 16 bees; BioBees, Hawke's Bay) was moved into the greenhouse on 20 August 2007 to facilitate pollination.

The experiment was a completely randomised block design with 5 replicates. There were four plants for each treatment plot and cultivar, with the four pots placed separately for each cultivar on a sterile plastic tray $(350 \times 300 \times 25 \mathrm{~mm})$. However, cultivars were paired for each treatment, with the front and back positions alternating on the five blocks.

\section{Pathogens}

Wild type isolates of Colletotrichum acutatum (isolate C5) and Botrytis cinerea (I39) from strawberry were used. Both isolates have a history of pathogenicity based on earlier unpublished work (M. Walter, Sustainable Farming Fund Grant 03/197). Colletotrichum 
was stored as conidial suspension in $20 \%$ glycerol at $-80^{\circ} \mathrm{C}$, and $B$. cinerea as mycelial plugs in sterile distilled water in the dark at room temperature. Pathogens were grown on potato dextrose agar (PDA, Merck) and incubated under a light bank at a 14:10 h day:night cycle at $20-23^{\circ} \mathrm{C}$. Conidia from 2 to 3 -week-old plates were harvested with sterile distilled water and filtered through sterile lens tissue to remove mycelial fragments. Spore concentrations $\left(2 \times 10^{5} \mathrm{conidia} / \mathrm{ml}\right)$ were adjusted with a haemocytometer. Viability tests (\% germination) were conducted on PDA in parallel with each disease bioassay.

\section{Physiological measurements}

The number of fully opened flowers was counted every 10 days starting on 24 August 2007. Foliar biomass was estimated by counting all leaf petioles half way through the experiment on 14 September 2007 and again upon completion of the trial on 1 November 2007. On the latter date, the foliar fresh and dry weights $\left(24 \mathrm{~h}\right.$ at $\left.60^{\circ} \mathrm{C}\right)$ were also determined. Fruit were picked twice a week (Monday and Thursday) when fully ripe ( $>95 \%$ red). Fruit numbers and weights were recorded on each picking day. Very small, damaged or diseased fruit were removed. The remaining unblemished fruit were then used for the disease susceptibility studies.

\section{Disease susceptibility}

Fruit within a treatment and cultivar were pooled from the five replicates and each fruit considered an experimental unit. Fruit were placed into surface sterilised single cell plastic compartments using kiwifruit Plix ${ }^{\circledR}$ trays (36 cells). For $C$. acutatum, the fruit was injured (1-2 mm) with a sterile needle prick on both fruit shoulders and inoculated with a droplet $(10 \mu \mathrm{l})$ of sterile distilled water on the left and $C$. acutatum spore suspension $\left(2 \times 10^{5}\right.$ conidia/ml $)$ on the right fruit shoulder. A droplet $(10 \mu \mathrm{l})$ of the $C$.acutatum spore suspension was also applied to the tip of the fruit, without the injury. For $B$. cinerea, fruit shoulders were inoculated with a droplet $(10 \mu \mathrm{l})$ of sterile distilled water and $B$. cinerea spore suspension $\left(2 \times 10^{5}\right.$ conidia/ml $)$, without the injury. Fruit were then incubated under high humidity on the laboratory bench at $20-23^{\circ} \mathrm{C}$. Rot assessments were done after 4 and 7 days of incubation by measuring lesion diameter $(\mathrm{mm})$ for C. acutatum and for B. cinerea lesion diameter and fruit colonisation (\%).

Leaf susceptibility was determined at the conclusion of the experiment. The youngest, fully expanded trifoliate leaf was collected from each plant. Leaves within a treatment and cultivar were pooled from the five replicates and each trifoliate leaf considered an experimental unit. Leaves were surface sterilised for $1 \mathrm{~min}$ in ethanol $(95 \%)$ followed by 3 min in a sodium hypochlorite solution (1\%). Leaves were then rinsed in tap water and allowed to dry on sterile paper towels. Leaves were subsequently halved and placed onto new trays lined with moist, sterile paper towels for Botrytis or Colletotrichum assays. Each leaflet of a trifoliate leaf was injured on either side (mid point) of the main vein with the hot tip of an engraving needle by briefly (1 s) touching the upper leaf surface. The resulting necrotic areas on each leaflet were then inoculated with a droplet $(15 \mu \mathrm{l})$ of sterile distilled water and pathogen spore suspension $\left(2 \times 10^{5}\right.$ conidia/ml). Leaves were incubated at high humidity on the laboratory bench at $20-23^{\circ} \mathrm{C}$. Lesion expansion (\% incidence) was assessed after 7 and 10 days of incubation.

\section{Statistical analyses}

The effects of nitrogen type and nitrogen concentration on physiological and disease measures were assessed using mixed-model ANOVAs. These models tested the effects of cultivar, and nitrogen treatment as fixed factors, and used the appropriate replicate unit (e.g. block, leaf or plant) as a random factor. In some instances (e.g. the development of lesion diameters) model terms were used to reflect the repeated measures form of the temporal comparisons. Data are summarised as least-squares means derived from the ANOVA models, and pair-wise comparisons were undertaken among these means as indicated using least significant difference tests. The appropriateness of these parametric analyses was confirmed by visual examination of the residual plots generated from the ANOVA models. $\mathrm{P}<0.05$ was taken to indicate statistical significance. 


\section{RESULTS}

Trends observed were very similar for both cultivars, therefore data were pooled. Flowering started in August; the first flush occurred in early September, the second in late September and the third flush in late October. This pattern was quite apparent for the high nitrogen treatments. Plants in the control treatments did not have a third flush. From the 20 plants per cultivar and treatment (4 plants per plot with 5 replicates), control treatments only produced approximately 1 flower per plot compared with approximately 4-5 flowers per plot for the high nitrogen treatments (Fig. 1). While these plants also kept producing new flower trusses, the experiments ceased in November because control plants were 'exhausted'. For the period monitored (24 August-29 October 2007), more flowers were produced $(\mathrm{P}<0.001)$ in plants that received nitrogen $(7.1$ flowers/plant $)$ than in the control treatments (4.5 flowers/plant), with somewhat more (but not significantly different for this period, $\mathrm{P}>0.05$ ) flowers in the high nitrogen treatments ( 7.3 flowers/plant) than in the low nitrogen treatments (6.5 flowers/plant). Nitrogen type was less important than the presence and concentration of $\mathrm{N}(\mathrm{P}<0.001)$. Similarly, more fruit were produced $(\mathrm{P}<0.001)$ in treatments containing nitrogen than in the control treatments (Fig. 2), with more fruit ripening in the high nitrogen than in the low nitrogen treatments. 'Ventana' produced more fruit (5.7 fruit/plant) with larger berries (12.1 g/fruit) than 'Camarosa' ( 5 fruit/plant; $10 \mathrm{~g} /$ fruit $)$ under the conditions tested $(\mathrm{P}<0.01)$. Berry size increased $(\mathrm{P}<0.001)$ with increasing nitrogen concentration, but nitrogen source itself was not important (Fig. 3). Foliar biomass was also affected by nitrogen concentration $(\mathrm{P}<0.001)$, but not by nitrogen source, as demonstrated by the dry weights (Fig. 4). These trends were also true for fresh weight measurements and leaf counts (data not shown). There was no cultivar effect on foliar biomass ( $\mathrm{P}>0.05)$, although 'Ventana' plants produced more leaves (32 leaves/plant) than 'Camarosa' (24 leaves/plant; $\mathrm{P}<0.001)$

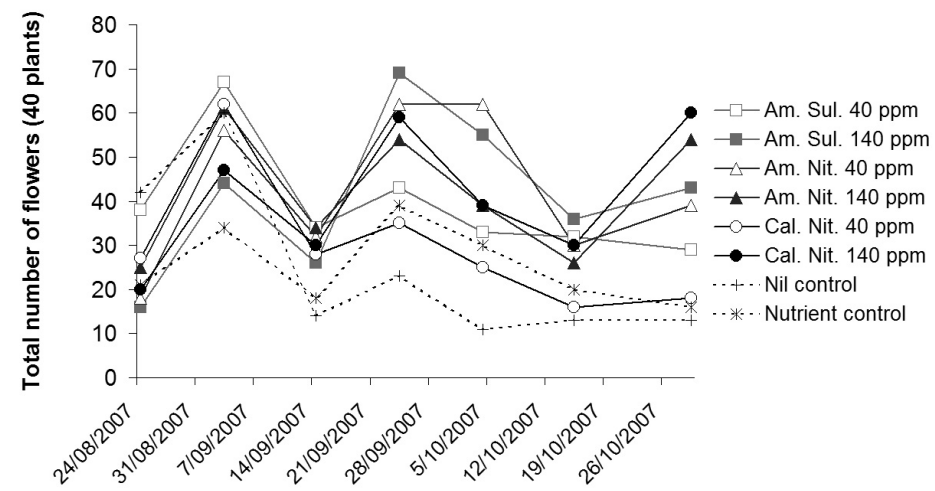

FIGURE 1: The total number of flowers counted for three nitrogen types (ammonium nitrate, ammonium sulphate or calcium nitrate) at two nitrogen concentrations (40 or $140 \mathrm{ppm} \mathrm{N}$ ) along with control treatments. Values are from $\mathbf{4 0}$ plants (four plants/plot for the two cultivars with five replicates). Strawberry plants were grown in sand in a glasshouse and nutrient solutions applied three times per week. 


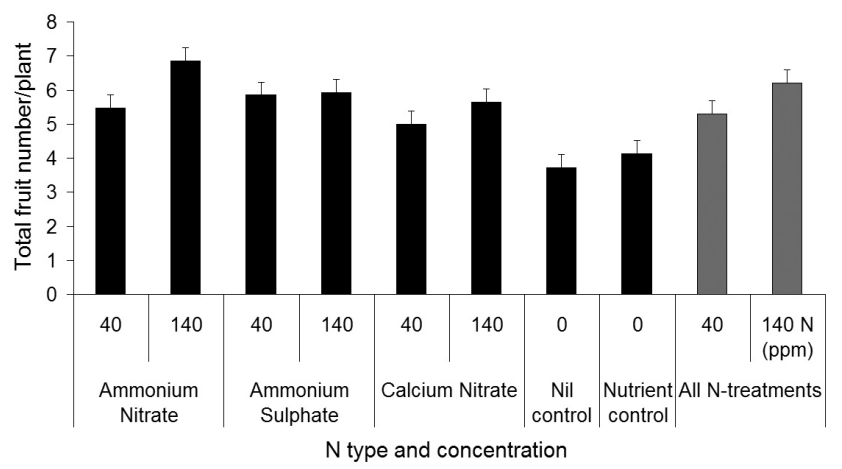

FIGURE 2: The total number of strawberry fruit/plant counted for three nitrogen types (ammonium nitrate, ammonium sulphate or calcium nitrate) at two nitrogen concentrations $(40$ or $140 \mathrm{ppm} \mathrm{N})$ along with control treatments. Also shown are overall means for low and high nitrogen treatments. Values are from $\mathbf{4 0}$ plants (four plants/plot for the two cultivars with five replicates) with standard error bars indicated. Strawberry plants were grown in sand in a glasshouse and nutrient solutions applied three times per week.

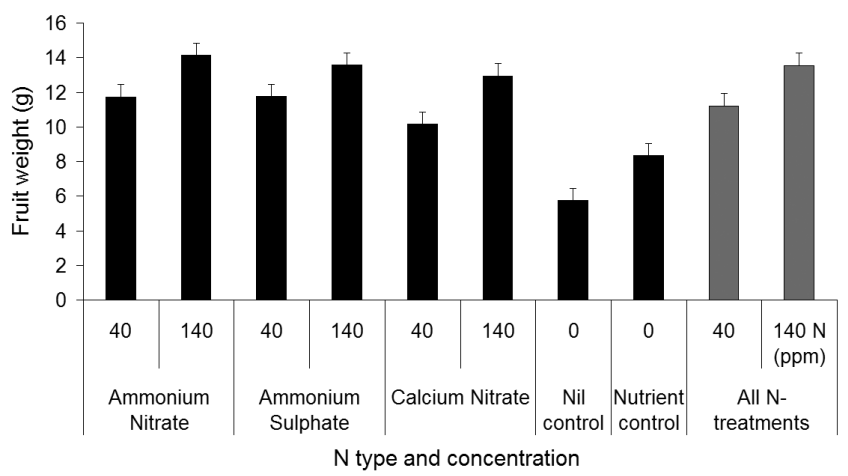

FIGURE 3: Mean fresh weight of strawberry fruit (g) for three nitrogen types (ammonium nitrate, ammonium sulphate or calcium nitrate) at two nitrogen concentrations (40 or $140 \mathrm{ppm} \mathrm{N}$ ) along with control treatments. Also shown are overall means for low and high nitrogen treatments. Values are from $>\mathbf{1 6 0}$ fruit for each treatment (pooled from two cultivars and all harvests) with standard error bars indicated. Strawberry plants were grown in sand in a glasshouse and nutrient solutions applied three times per week. 


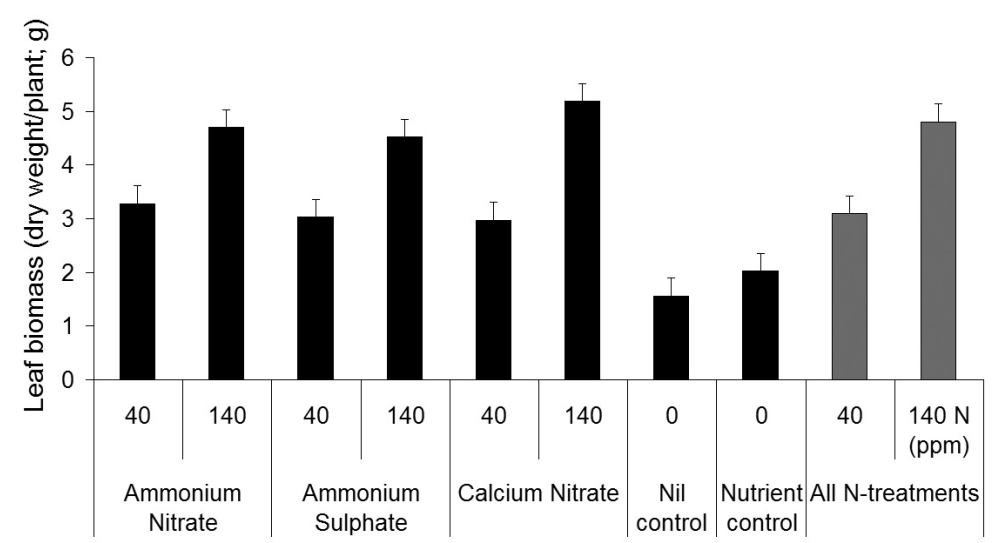

$\mathrm{N}$ type and concentration

FIGURE 4: Mean leaf biomass of strawberry plants ( $g$ dry weight/plant) for three nitrogen types (ammonium nitrate, ammonium sulphate or calcium nitrate) at two nitrogen concentrations $(40$ or $140 \mathrm{ppm} \mathrm{N})$ along with control treatments. Also shown are overall means for low and high nitrogen treatments. Values are from 40 plants (four plants/plot for the two cultivars with five replicates) with standard error bars indicated. Strawberry plants were grown in sand in a glasshouse and nutrient solutions applied three times per week.

In contrast to the physiological observations (as described above), where the presence of nitrogen was more important than the type of the nitrogen source, disease susceptibility was affected by both nitrogen concentration and nitrogen type. These trends were observed for both pathogens, both cultivars and both assessment days. Therefore, data were pooled for the two cultivars, and disease data are presented for the second assessment, as differences were more apparent. In water-inoculated fruit or leaf treatments, only a few fruit or leaflets developed any disease symptoms. Therefore, water treatments were ignored in the data analyses.

At the high nitrogen concentration, anthracnose lesions were generally larger in plants in the ammonium sulphate, followed by the ammonium nitrate and then calcium nitrate treatments. This was true for both wounded and non-wounded treatments (Fig. 5). However, the effect of nitrogen concentration on anthracnose development was more noticeable in non-wounded inoculation sites, and the effect of nutrient source was more noticeable in wounded treatments (Fig. 5). 'Camarosa' was more susceptible $(\mathrm{P}<0.01)$ to anthracnose fruit rot than 'Ventana', with lesion sizes measuring 10.2 and $5.4 \mathrm{~mm}$ for wounded and non-wounded 'Camarosa' inoculations, compared with 'Ventana' lesion sizes of 8.1 and $4.1 \mathrm{~mm}$ for wounded and non-wounded inoculations, respectively.

Fruit susceptibility to $B$. cinerea was also affected by nitrogen concentration and nitrogen type (Fig. 6). Grey mould was greatest in high nitrogen treated plants, with the largest lesions being found in the ammonium nitrate, followed by the ammonium sulphate and then calcium nitrate treatments. Grey mould was greater $(\mathrm{P}<0.001)$ in inoculated 'Ventana' (39.9\%) than 'Camarosa' (28.4\%) fruit. 


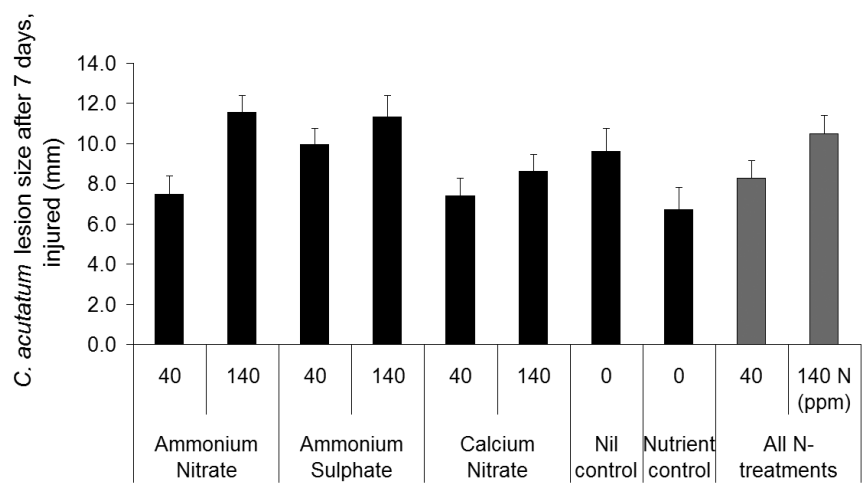

$\mathrm{N}$ type and concentration

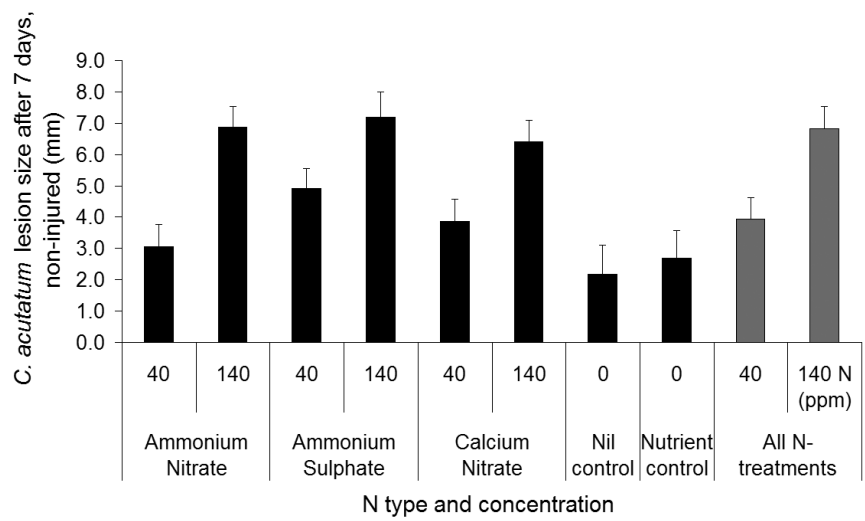

FIGURE 5: Mean lesion size of strawberry fruit $(\mathrm{mm})$ inoculated with Colletotrichum acutatum with injury (top) and without injury (bottom) for three nitrogen types (ammonium nitrate, ammonium sulphate or calcium nitrate) at two nitrogen concentrations (40 or $140 \mathrm{ppm} \mathrm{N}$ ) along with control treatments. Also shown are overall means for low and high nitrogen treatments. Strawberry fruit were injured with a sterile needle and inoculated with $10 \mu \mathrm{l}$ spore suspension on the right side of the fruit shoulder and a water droplet on the left side of the fruit shoulder. For the non-injured treatment, fruit tips were inoculated. Fruit were incubated at room temperature for 7 days and lesion size measured. Values are from $>60$ fruit for each treatment (pooled from two cultivars and all harvests) with standard error bars indicated. Strawberry plants were grown in sand in a glasshouse and nutrient solutions applied three times per week.

Similar trends were observed for leaf susceptibility to the two pathogens. Again, nitrogen concentration and source affected the ability of $C$. acutatum $(\mathrm{P}<0.10)$ and B. cinerea $(\mathrm{P}<0.001)$ to colonise strawberry leaves (Fig. 7). Again, high nitrogen benefited the diseases with - at the high nitrogen concentration - calcium nitrate-treated plants 
showing the least colonisation by the pathogens, particularly noticeable in the case of B. cinerea (Fig. 7). There was no cultivar difference in leaf sensitivity to C. acutatum leaf lesion development. However, more Botrytis leaf lesions developed $(\mathrm{P}<0.01)$ in treated 'Ventana' $(5.7 \%)$ than 'Camarosa' $(5 \%)$ leaves.

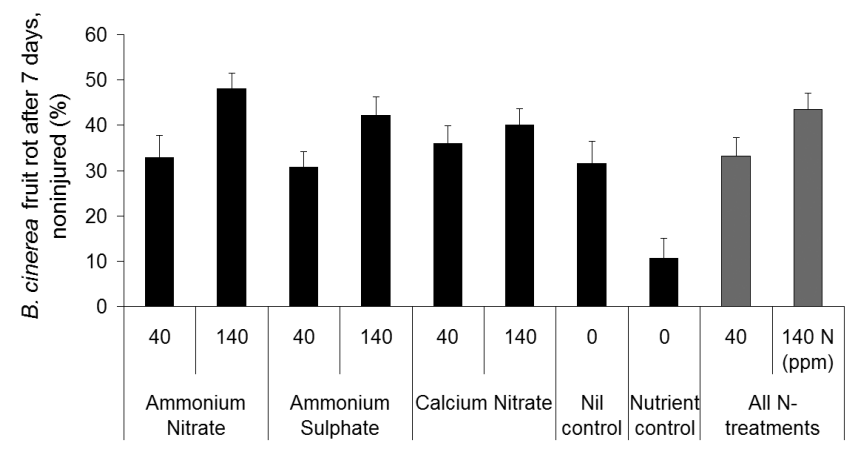

$\mathrm{N}$ type and concentration

FIGURE 6: Mean proportion of strawberry fruit rot (\%) inoculated with Botrytis cinerea for three nitrogen types (ammonium nitrate, ammonium sulphate or calcium nitrate) at two nitrogen concentrations (40 or $140 \mathrm{ppm} \mathrm{N}$ ) along with control treatments. Also shown are overall means for low and high nitrogen treatments. Strawberry fruit were inoculated (non-injured) with $10 \mu \mathrm{l}$ spore suspension on the right side of the fruit shoulder and a water droplet on the left side of the fruit shoulder. Fruit were incubated at room temperature for 7 days and fruit rot $(\%)$ estimated. Values are from $>80$ fruit for each treatment (pooled from two cultivars and all harvests) with standard error bars indicated. Strawberry plants were grown in sand in a glasshouse and nutrient solutions applied three times per week.

\section{DISCUSSION AND CONCLUSION}

As expected, the typical plant flowering and yield responses to nitrogen fertilisation were observed. There was also an increase in disease susceptibility with increasing $\mathrm{N}$ concentrations, and plant physiological responses were not affected by nitrogen type although disease responses were. This confirms previous work in strawberry where susceptibility to Colletotrichum spp. was affected by nitrogen source and concentration (Smith 1989). As a direct result of this work, strawberry growers in Louisiana and Mississippi, USA, use calcium nitrate as their preferred nitrogen source to help manage anthracnose disease. The present trial demonstrates that this practice will also be useful in New Zealand to control strawberries affected by Colletotrichum spp.

In New Zealand, grey mould rather than anthracnose is the major strawberry fruit pathogen (Timudo-Torrevilla et al. 2005). The pathogen infects the fruit during flowering, thereby establishing latent infections, and/or at harvest, causing a surface fruit rot. The present data suggest that calcium nitrate may be a suitable source for nitrogen that will also help growers to reduce disease risk caused by $B$. cinerea. While the fertiliser does not prevent fruit infection and fruit rots, nor act as a fungicide, it seems to improve the plants' own defence mechanisms. This beneficial effect is probably attributed to the level of calcium in the plant (Smith \& Gupton 1993). In summer fruit, foliar pre-harvest calcium chloride applications were found beneficial for control of brown rot caused by Monilinia fructicola (Elmer et al. 2007). The difference between the B. cinerea fruit rot in the nil control and the nutrient control is interesting. Calcium and/or perhaps the 
potassium in the nutrient control may protect the fruit from rotting, i.e. the increasing calcium and/or potassium may enhance the plant defence. Cytosolic free $\mathrm{Ca}^{2+}$ is known to be an important secondary messenger playing a crucial role in plant responses to various stresses, including the biotic stress induced by pathogens (Reddy \& Reddy 2004). This provides a possible mechanistic link with the reduced susceptibility of fruit treated with calcium nitrate. In the studies described here, it was probably the lack of nutrient in the water control that increased the plants' vulnerability to pathogens. The water control plants were nutrient deficient and thus very susceptible to disease.

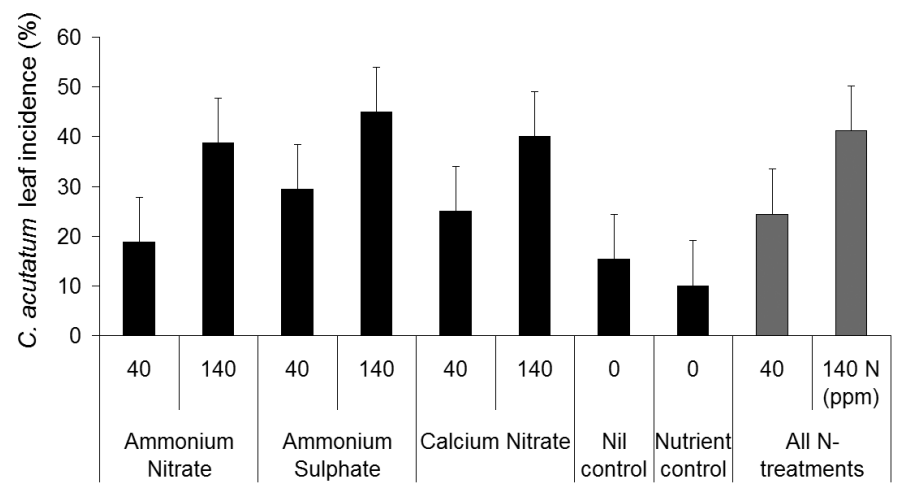

$\mathrm{N}$ type and concentration

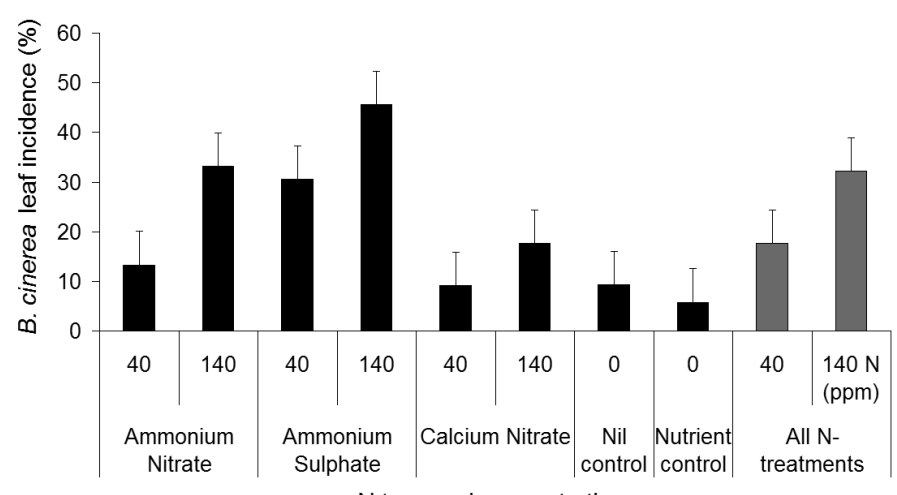

$\mathrm{N}$ type and concentration

FIGURE 7: Lesion incidence of strawberry leaves (\%) inoculated with Colletotrichum acutatum (top) and Botrytis cinerea (bottom) for three nitrogen types (ammonium nitrate, ammonium sulphate or calcium nitrate) at two nitrogen concentrations $(40$ or $140 \mathrm{ppm} \mathrm{N})$ along with control treatments. Also shown are overall means for low and high nitrogen treatments. Artificially created necrotic leaf lesions were inoculated with $15 \mu \mathrm{l}$ spore suspension. Leaves were incubated at room temperature for 7-10 days and incidence $(\%)$ of leaf lesion expansion assessed. Values are from 20 leaves with 3 leaflets each for each treatment (pooled from two cultivars) with standard error bars indicated. 
A New Zealand commercial strawberry grower may apply as much as $150-200 \mathrm{~kg} \mathrm{~N} / \mathrm{ha}$, or approximately 2-3 g N/plant for the growing season. In the 4-month period of the present trial, the total level of nitrogen received was in the order of $0.3 \mathrm{~g} / \mathrm{plant}$ for the high nitrogen treatments. Clearly, the potential beneficial effect of calcium nitrate needs to be further investigated at commercial nitrogen rates as well as in the field. The aim of showing that nitrogen type can affect disease susceptibility was achieved. The applicability thereof warrants further investigation in strawberry and other berries. Reduction in disease risk by fertilisation and choice of nitrogen source is a highly tangible approach.

\section{ACKNOWLEDGEMENTS}

This work was jointly funded by New Zealand Strawberry Growers Inc. and the Ministry of Agriculture and Forestry via a Sustainable Farming Fund (SFF L07/070). Thanks to Dr CM Frampton, Christchurch School of Medicine, University of Otago for statistical analyses.

\section{REFERENCES}

Elmer PAG, Spiers TM, Wood PN 2007. Effects of pre-harvest foliar calcium sprays on fruit calcium levels and brown rot of peaches. Crop Protection 26 (1): 11-18.

Howard CM, Maas JL, Chandler CK, Albregts EE 1992. Anthracnose of strawberry caused by the Colletotrichum complex in Florida. Plant Disease 76: 976-981.

Keller M, Kummer M, Vasconcelos MC 2001. Reproductive growth of grapevines in response to nitrogen supply and rootstock. Australian Journal of Grape and Wine Research 7 (1): 12-18.

Maas JL 1998. Compendium of strawberry diseases. $2^{\text {nd }}$ ed. APS Press, St Paul, USA. $98 \mathrm{pp}$.

Reddy VS, Reddy ASN 2004. Proteomics of calcium-signaling components in plants. Phytochemistry 65:1745-1776.

Smith BJ 1989. Effect of nitrogen source and level on the severity of strawberry anthracnose to crown rot. Phytopathology 79: 376 (abstract).

Smith BJ, Gupton CL 1993. Calcium applications before harvest affects the severity of anthracnose fruit rot greenhouse grown strawberries. Acta Horticulturae 348: 477-482.

Timudo-Torrevilla OE, Everett KR, Waipara NW, Boyd-Wilson KSH, Langford GI, Walter M 2005. Present status of strawberry fruit rot diseases in New Zealand. New Zealand Plant Protection 58: 74-79. 